\title{
Blocking of first- and second-order autoshaping in pigeons
}

\author{
C. M. LEYLAND and N. J. MACKINTOSH \\ University of Sussex, Brighton, Sussex, BN1 9QY, England
}

\begin{abstract}
In Experiment 1, the development of autoshaped pecking to a keylight signaling food was blocked if the keylight was presented only in conjunction with another stimulus already established as a signal for food, even though the blocking stimulus (either an overhead light or a train of clicks) never elicited pecking itself. In Experiment 2, pigeons came to peck a white keylight which signaled the presentation of a red keylight which had earlier been established as a first-order signal for food, but this second-order autoshaping was blocked if the white keylight was presented only in conjunction with the houselight or clicker which had previously signaled the presentation of the first-order stimulus. Second-order autoshaping was thus blocked in the same way as was first-order autoshaping.
\end{abstract}

In Kamin's (1969) experiments on conditioned suppression in rats, prior conditioning to one element of a compound CS interfered with or blocked conditioning to the second element. Rats conditioned to a noise-light compound showed reliable suppression when subsequently tested with, say, the noise; but if they had previously been conditioned to the light alone, they showed significantly less suppression to the noise after an equivalent amount of compound conditioning.

Interesting experiments on the blocking of appetitive conditioning have been carried out by Blanchard and Honig (1976) and Tomie (1976a, 1976b). They showed that delivery of free food in the presence of a variety of contextual stimuli interfered with the development of keypecking when pigeons were subsequently autoshaped to peck at a keylight in the presence of these contextual stimuli. Prior conditioning of the contextual stimuli, which included a diffuse colored houselight (Blanchard \& Honig, 1976), an auditory stimulus (Tomie, 1976b), and general apparatus cues (Tomie, 1976a, 1976b), blocked subsequent conditioning to the keylight. These experiments had one notable advantage over those of Kamin. In order to assess the effectiveness of blocking of conditioned suppression, it is necessary to give test trials with the blocked element of the compound presented alone. It is conceivable that experimental subjects fail to respond in such a test because they have learned to respond only to the compound training stimulus. In Blanchard and Honig's experiment, however, the diffuse blocking stimulus did not itself control any keypecking and thus the development of conditioning to the blocked stimulus could be direct-

This research was supported by grants from the U.K. Science Research Council. Requests for reprints should be sent to N. J. Mackintosh. ly observed in the course of compound conditioning trials.

The present paper reports two experiments. In the first, we studied blocking of autoshaping to a localized keylight by a diffuse auditory or visual stimulus which did not itself control any keypecking. Both experimental and control groups were initially conditioned with one such diffuse stimulus signaling food. For the experimental group, compound trials involved presenting the keylight in conjunction with this pretrained stimulus. For the control group, a different diffuse stimulus was presented with the keylight on compound trials. This experiment replicates those of Blanchard and Honig (1976) and Tomie (1976a, 1976b) but employes a discrete-trial procedure (more similar to that used by Kamin, 1969) for conditioning the blocking stimuli. It also provides a necessary preliminary to examining, in Experiment 2, the blocking of second-order autoshaping.

The work of Rizley and Rescorla (1972) has revived interest in second-order conditioning. Studies of second-order conditioning in pigeons (Leyland, 1977; Rashotte, Griffin, \& Sisk, 1977) have established that pigeons will come to peck a keylight $\left(\mathrm{S}_{2}\right)$ which is paired with the presentation of another stimulus $\left(S_{1}\right)$ previously paired with food. This latter pair of studies has established a fundamental structural similarity between first- and second-order autoshaping, each of which depends largely on a direct association between the stimuli being paired. In order to extend our knowledge of the parallel between these processes, we here compare blocking of first- and secondorder autoshaping.

\section{EXPERIMENT 1}

Two groups of birds were conditioned using either a clicker or a change in houselight color paired with food. They subsequently received conditioning trials 
to a compound CS consisting of a red keylight and either that stimulus previously conditioned in Phase 1 (Group B) or that stimulus not yet conditioned Group C).

\section{Method}

Subjects. The subjects were 16 experimentally naive feral pigeons, male and female, maintained at $75 \%$ of their free-feeding weights. Water and grit were continuously available in their individual home cages, which were housed in a room illuminated at all times. The subjects were run between the hours of 1000 and 2000.

Apparatus. Two conventional $30.5 \times 30.5 \times 30.5 \mathrm{~cm}$ pigeon chambers with grid floor, clear Perspex rear wall, opal Perspex roof, and matt black walls were used. These are described in more detail elsewhere (Leyland, 1977). They were diffusely illuminated by a $60-\mathrm{W}$ tungsten filament strip light, operated at $110 \mathrm{~V}$, mounted above the opal Perspex ceiling, and white masking noise at $80 \mathrm{~dB}$ (re $20 \mu \mathrm{N} / \mathrm{m}^{2}$ ) was provided from a speaker mounted above the grain magazine.

The chambers contained two response keys, but the left-hand one was blanked off and only the right-hand one was used. It could be illuminated by $24-\mathrm{V}, 2.8-\mathrm{W}$ bulbs mounted in a threecolor display unit.

The stimuli used in the experiment were as follows: The illumination of the right-hand key in red or white; a train of clicks, provided by the activation at $5 \mathrm{~Hz}$ of a relay clicker mounted on the outside of the left-hand wall of the box, midway up at the rear end; a change in color of overall illumination of the chamber from white to blue, produced by switching off the overhead striplight and switching on a second striplight mounted parallel to the first, masked with blue cellophane and operated at $230 \mathrm{~V}$. Stimulus presentations were $8 \mathrm{sec}$ long, and reinforcement consisted of $4 \mathrm{sec}$ access to mixed grain, during which the magazine was illuminated with a white light.

The chambers were housed in sound-attenuating boxes, and programming and recording were carried out automatically by equipment housed in an adjoining room.

Procedure. Magazine training procedure was identical for both experiments and was quite extensive, since autoshaping is often irregular and slow to develop in birds which have not been thoroughly magazine trained. After a preliminary session in which the birds were shaped by hand to eat from the magazine, there were four subsequent sessions of variable time (VT) 30 -sec delivery of food. In this schedule, food was delivered independent of any response at variable intervals averaging $30 \mathrm{sec}$. Each session terminated after 50 food deliveries or after a criterion of eating $23 / 25$ deliveries was met. Each bird had to meet this criterion within the first 25 trials of both Sessions 3 and 4; otherwise, further sessions were given until the criterion was met on two consecutive sessions. All birds in both experiments satisfied this criterion within six sessions, and it was very rare for a bird to require more than the basic four sessions to do so.

Phase 1 began on the day following the last session of magazine training. There were two sessions, with 60 trials per session and a variable intertrial interval averaging $30 \mathrm{sec}$. Each trial consisted of the presentation of an 8 -sec stimulus immediately followed by $4 \mathrm{sec}$ access to food. For half the subjects, this stimulus was the clicker, and for half, the blue houselight.

In Phase 2, which followed immediately after Phase 1 , there were three 60-trial sessions, in which a compound stimulus, consisting of the illumination of the red keylight and either the clicker or the blue houselight preceded each food delivery. For Group B (blocked), the keylight was presented in conjunction with the stimulus to which they had been exposed in Phase 1; for Group C (control), the stimulus not used in Phase 1 was presented in conjunction with the keylight in Phase 2. Appropriate counterbalancing insured that half the subjects in each group were trained with the keylight-clicker compound, and half with the keylighthouselight compound.

\section{Results}

Observation of subjects during Phase 1 revealed no evidence of pecking directed at the key or at any other part of the apparatus. Subjects conditioned to the clicker generally stood near the food magazine during presentation of the stimulus, while those conditioned to the houselight sometimes craned their necks towards the ceiling (cf. Leyland, 1977).

Within Groups B and C, there were no differences between subgroups trained with clicker or with blue houselight in Phase 1. The data for these subgroups were therefore combined. Responding to the red keylight for each group throughout Phase 2, is shown in Figure 1. Group B showed no evidence of autoshaping at all. Although Group $C$ appears to have been slower to autoshape than the birds trained by Leyland (1977) with similar procedures in the same apparatus, there is a clear difference between the performance of the two groups. Subjects of Group C took fewer trials to their first response (median 34.5 ) than those in Group B (median 85.0) $(\mathrm{U}=10, \mathrm{p}<.01)$, and over all three sessions produced more keypecks to the red light $(\mathrm{U}=13, \mathrm{p}<.025)$.

The difference between Groups $B$ and $C$ shows that autoshaping was blocked by the presence of a discrete stimulus already established as a signal for food. The apparently low level of performance in Group C may be attributed either to overshadowing of the keylight by the untrained second component or to some more general effect of Phase 1 training. The results of this experiment are similar to those reported by Tomie (1976b, Experiment III), who found that autoshaping was slower to develop in a group conditioned in the presence of a stimulus already established as a signal for food (like the present Group B) than in a group given comparable prior experience in the presence of a different stimulus (like the present Group C), but also included a con-

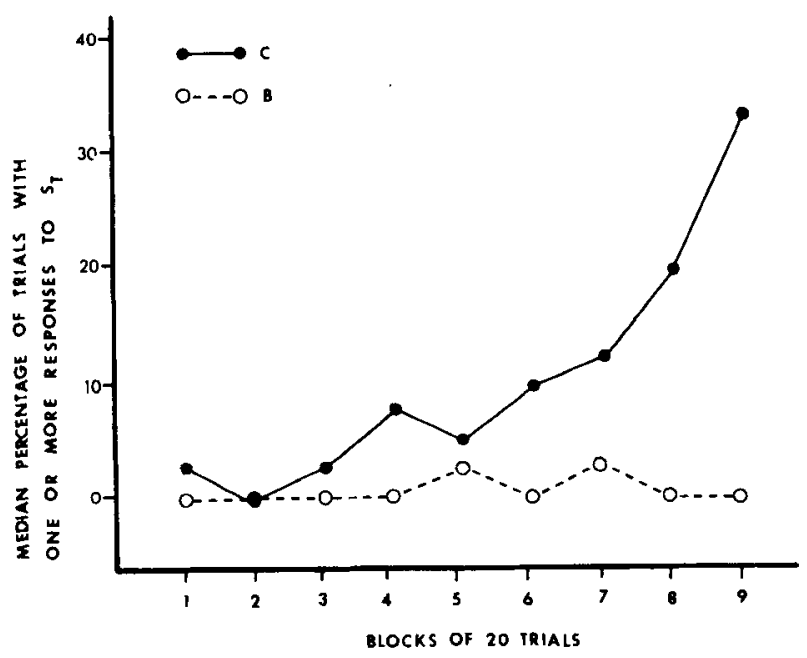

Figure 1. Median percentage of trials with one or more responses to the red keylight during Phase 2 of Experiment 1. 
trol group without prior experience which autoshaped faster than either of the other groups. The deleterious effect of extended training with free food prior to autoshaping may be the consequence of a state of "learned laziness," as suggested by Engberg, Hansen, Welker, and Thomas (1972), but it is equally possible that it also represents a blocking effect. Even if, as in the present experiment, the delivery of food is signaled by a discrete stimulus, some conditioning may occur to contextual stimuli which would still be present during subsequent autoshaping to interfere with the course of conditioning to the keylight.

\section{EXPERIMENT 2}

Using the same general procedures as those of Experiment 1, Experiment 2 was designed to look for evidence of similar blocking of second-order conditioning. This would be demonstrated if pecking failed to develop to $S_{2}$ when paired with $S_{1}$, if $S_{2}$ was presented only in conjunction with another stimulus already established as a signal for $S_{1}$.

\section{Method}

Subjects and Apparatus. Ten experimentally naive pigeons were used in this experiment. Other details of subjects and apparatus were identical to those of Experiment 1.

Procedure. The general procedure was similar to that of the first experiment. Phase 1 immediately followed magazine training, and consisted of two sessions of first-order autoshaping to a red key $\left(S_{1}\right)$; in the first session, food was delivered on each of the 60 trials, but in the second session food was available on only $50 \%$ of trials according to Gellermann sequences. Phase 2 was designed to establish one of the nonlocalized stimuli $\left(\mathrm{S}_{2} \mathrm{~B}\right)$ as a second-order CS. All birds received a single session containing 60 pairings of $S_{2} B$ and $S_{1}$, interspersed with 30 first-order "refresher" trials. There were six blocks of 15 trials; the first 5 trials of each block were refresher trials on which $S_{1}$ was paired with food on $50 \%$ of the trials; the remaining 10 trials consisted of pairings of $S_{2} B$ and $S_{1}$. For six birds, the nonlocalized stimulus encountered in Phase 2 was the change in color of the houselight, and for the other four, it was a train of clicks. Half of the animals receiving each of these stimuli were then assigned to each of two groups of five.

Phase 3 was given in a single session and consisted of 40 compound second-order conditioning trials interspersed, as in Phase 2, with 20 first-order refresher trials. On the second-order trials, the presentation of a compound CS consisting of one of the nonlocalized stimuli and a white keylight, the test stimulus $\left(S_{2} T\right)$, was immediately followed by the presentation of $S_{1}$. For Group B, the nonlocalized stimulus used in the compound was that previously conditioned in Phase $2\left(S_{2} B\right)$. For Group $C$, the nonlocalized stimulus used in the compound $\left(\mathrm{S}_{2} \mathrm{C}\right)$ was that not previously encountered.

\section{Results}

The groups did not differ in terms of responding to $S_{1}$ during any phase of the experiment: In Phase 1 , Group C responded on $62.0 \%$ and Group B on $49.5 \%$ of trials; in Phase 2, these scores were $67.7 \%$ and $71.7 \%$, respectively; and in Phase 3 , they were $86.5 \%$ and $72.3 \%$, respectively. None of these differences was significant. There were no differences within Groups B or C between the subgroups which encountered the clicker or blue houselight as $\mathrm{S}_{2} \mathrm{~B}$. The data for these subgroups were therefore combined. The proportion of trials on which subjects responded to the white keylight during Phase 3 is shown in Figure 2. Group $C$ responded more to this stimulus than did Group B $(U=4, p<.05)$. It is interesting to note that this difference is entirely due to the scores over the last two blocks $(U=2, p<.025)$, whereas on the first two blocks there was no difference between the two groups $(U=11, p>.4)$. The most plausible explanation is that pecking occurred to $S_{2} T$ on early trials because of generalization from $S_{1}$ (cf. Leyland, 1977). In Group B, such generalized pecks extinguished for lack of effective reinforcement, but in Group $C$ the contingency between $\mathrm{S}_{2} \mathrm{~T}$ and $S_{1}$ resulted in the acquisition of conditioned pecking to $\mathrm{S}_{2} \mathrm{~T}$.

\section{DISCUSSION}

Experiment 1 confirmed that the development of autoshaped pecking to a keylight signaling the delivery of food is blocked if the keylight is presented only in conjunction with another stimulus previously established as a signal for food. As in Blanchard and Honig's (1976) and Tomie's (1976a, 1976b) experiments, there was no suggestion in the present experiment that the blocking stimulus itself controlled pecking. That the presence of one stimulus may block conditioning to another even though the two stimuli control quite different conditioned responses has also been shown by Holland (1977). If we accept that blocking arises because the occurrence of reinforcement is already predicted by the blocking stimulus (Kamin, 1969), it follows that different stimuli can serve as functionally equivalent predictors of reinforcement even though they control quite differ-

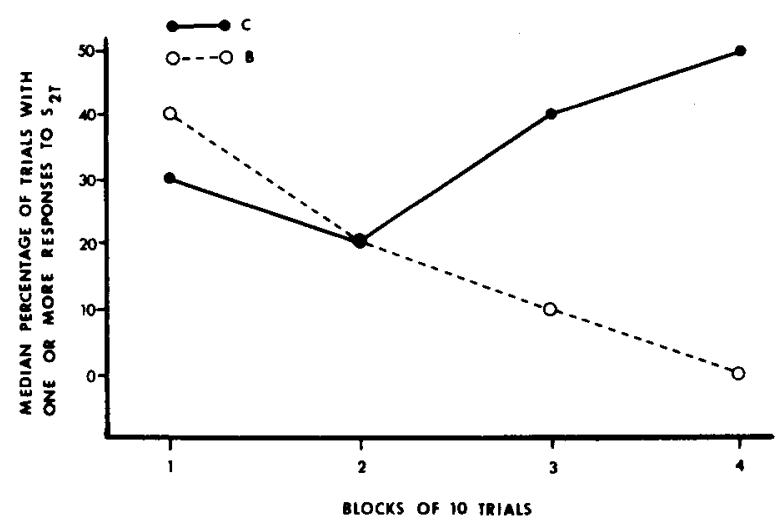

Figure 2. Median percentage of trials with one or more responses to the white keylight during Phase 3 of Experiment 2. 
ent overt responses. The implication, as Holland (1977) has noted, is that we should distinguish between what is learned about a stimulus, i.e., how it is associated with a reinforcer and how such associations generate changes in behavior.

The major finding of the present paper is that procedures similar to those used to produce blocking of first-order autoshaping will also block secondorder autoshaping, if the occurrence of the firstorder stimulus is already predicted by another second-order stimulus. Once again, the second-order blocking stimulus never elicited the pecking responses whose development to the second-order test stimulus it was able to block. Neither Experiment 1 nor Experiment 2 was designed as a critical test of competing theories of blocking; rather, they use the phenomenon of blocking as a diagnostic tool. We already know, from the work of Leyland (1977) and Rashotte et al. (1977), that first- and secondorder conditioning involve essentially similar processes. The present results reinforce this conclusion, and show further that those processes are sufficiently complex to yield some of the phenomena of selective association.

\section{REFERENCES}

Blanchard, R., \& Honig, W. K. Surprise value of food determines its effectiveness as a reinforcer. Journal of
Experimental Psychology: Animal Behavior Processes, 1976, 2. 67-74.

Engberg, L. A., Hansen, G., Welker, R. L., \& Thomas, D. R. Acquisition of key-pecking via autoshaping as a function of prior experience: “Learned laziness"? Science, 1972, 178, $1002-1004$.

Holland, P. C. Conditioned stimulus as a determinant of the form of the Pavlovian conditioned response. Journal of Experimental Psychology: Animal Behavior Processes, 1977, 3, 77-104.

Kamin, L. J. Predictability, surprise, attention and conditioning. In B. A. Campbell \& R. M. Church (Eds.), Punishment and aversive behavior. New York: Appleton-Century-Crofts, 1969.

LEYLAND, C. M. Higher order autoshaping. Quarterly Journal of Experimental Psychology, 1977, 29, 607-619.

Rashotte, M. E., Griffin, R. W., \& Sisx, C. L. Second-order conditioning of the pigeon's keypeck. Animal Learning \& Behavior, 1977, 5, 25-38.

Rizley, R. C., \& Rescorla, R. A. Associations in second-order conditioning and sensory preconditioning. Joumal of Comparative and Physiological Psychology, 1972, 81, 1-11.

Tomie, A. Retardation of autoshaping: Control by contextual stimuli. Science, 1976, 192, 1244-1246. (a)

Tomie, A. Interference with autoshaping by prior context conditioning. Joumal of Experimental Psychology: Animal Behavior Processes, 1976, 2, 323-335. (b)

(Received for publication September 2, 1977; revision accepted March 27, 1978.) 